\title{
Modification of Waste Aggregate PET for Improving the Concrete Properties
}

\author{
Zoe Harmonie Lee, ${ }^{1}$ Suvash Chandra Paul $\mathbb{D}^{1},{ }^{1,2}$ Sih Ying Kong ${ }^{D},{ }^{1}$ Susilawati Susilawati, \\ and Xu Yang ${ }^{3,4}$ \\ ${ }^{1}$ School of Engineering, Monash University Malaysia, Bandar Sunway 47500, Malaysia \\ ${ }^{2}$ Department of Civil Engineering, International University of Business Agriculture and Technology, Dhaka 1230, Bangladesh \\ ${ }^{3}$ School of Highway, Chang'an University, Xi'an 710064, China \\ ${ }^{4}$ Department of Civil Engineering, Monash University, Clayton, Victoria 3800, Australia
}

Correspondence should be addressed to Xu Yang; xyang2@mtu.edu

Received 24 June 2019; Accepted 26 November 2019; Published 19 December 2019

Academic Editor: Xuemei Liu

Copyright (c) 2019 Zoe Harmonie Lee et al. This is an open access article distributed under the Creative Commons Attribution License, which permits unrestricted use, distribution, and reproduction in any medium, provided the original work is properly cited.

\begin{abstract}
Disposal of plastic wastes causes negative impacts including degradation of land and ocean and climate change. Reusing plastic wastes in concrete is one of the effective methods of reducing plastic disposal. Polyethylene terephthalate (PET) is one of the most abundantly available plastic wastes as it is commonly used for plastic bottles and food containers. This paper investigates the effects of treating PET wastes using hydrogen peroxide solution $\left(\mathrm{H}_{2} \mathrm{O}_{2}\right)$ and calcium hypochlorite solution $\left(\mathrm{Ca}(\mathrm{ClO})_{2}\right)$ before incorporating in concrete as coarse aggregate replacements. The physical and mechanical properties of concrete were analyzed for three different percentages, namely, 10\%, 20\%, and 30\%, replacement of natural aggregates with plastic aggregates. For all percentage of replacements, it was found that chemically treated plastic aggregates have no effects on the fresh density, but the slump decreased due to roughened surface of treated plastic aggregates. Chemical treatment improved the bond strength between cementitious matrix and plastic aggregates and reduced the gap at the interfacial transition zone (ITZ). These phenomena contributed to the improvement the compressive strength and lower the permeability and porosity.
\end{abstract}

\section{Introduction}

Throughout the years, the quantity of plastic consumption has increased due to its reasonable cost, flexibility, durability, and global industrialization. According to a statistics done by the National Solid Waste Management Department of Malaysia, plastic wastes are the second largest of the total solid wastes produced in Malaysia [1]. The slow rate of degradation and the large amount of plastic wastes produced by human activities results in large area of landfills are required. Incineration is not a viable disposing method due to the toxic fumes released which is detrimental to the environment and human health. Recently, research have suggested reusing plastic wastes in concrete as natural aggregate replacement to reduce the exploitation of natural resources, and it could minimize the negative environmental impacts by construction [2]. Plastic wastes are cheap due to abundant in supply. Therefore, reusing plastic wastes as a substitution for natural aggregates is feasible because it is economical and environmental friendly. Commonly, two forms of plastics are used in concrete, namely, plastic aggregates and plastic fibres. Amongst the two, application of plastic aggregates is more economical and simpler as it generally involves less number of processing steps compared with that of fibres.

There are different types of plastic waste aggregates available for concrete applications. Polyethylene terephthalate (PET) is widely used domestically and discarded after single use. PET is normally used to manufacture plastic bottles, food containers, and cloth fibre. Research showed that incorporating plastic aggregates in concrete can be used for construction applications as it can reach strengths as high 
as that of normal concrete [3]. Alqahtani et al. [2] stated that substitution of PET in concrete could also be applied for construction of pavements and roads, where high strength is not required. Multiple studies were performed to study the incorporation of plastic waste in concrete, by replacing 10 to $30 \%$ of natural coarse aggregates. Subramani and Pugal [4] determined that a $20 \%$ percentage substitution was optimum, as the compressive strength decreased considerably when the plastic content was higher. Nevertheless, most studies just randomly replaced the plastic aggregates in concrete and observed their influences in mechanical and durability properties.

Incorporating plastic aggregates into concrete changes the consistency and homogeneity of mixture properties such as workability and density. Experiments performed by Saikia and de Brito [5] showed that the workability of fresh concrete was affected by the surface and texture of aggregates plastic aggregates. The smoother surface texture of plastic aggregates produced concrete with higher slump compared to typical concrete made from natural aggregates. Therefore, as the amount of plastic aggregates increased, the slump increased due to a larger area of smooth surface. It was also found that the density of concrete decreased proportionally with increasing replacement of plastic aggregates, as plastics have lower density than natural aggregates $[6,7]$.

It was reported that the strength contributed by recycled PET to the mixture was lower than natural fine aggregates [8]. The trend identified by research showed that the compressive strength reduced with increasing percentage of plastic aggregates in concrete. The reduction in compressive strength was caused by the weak adhesive strength between plastic aggregates and cement paste, due the hydrophobicity of plastics. The hydrophobicity also further restricted the diffusion of water into concrete, which was important for cement hydration [9]. Hannawi et al. [10] concluded that the large gaps at the interfacial transition zone (ITZ) in concrete with plastic aggregates reduced the concrete compressive strength.

Research findings concluded that the porosity and water permeability of concrete with plastic aggregates were higher than those of typical conventional concrete. Islam et al. [11] deduced that the weak bonding at the ITZ between cement paste and plastic aggregates contributed to higher porosity and permeability. During cement hydration, redistribution of calcium-silicate-hydrate (C-H-S) allows the pores in the ITZ to be partially filled. Depending on the width and content of aggregates, individual aggregates in ITZ can be interconnected, which highly affected the permeability and transport properties of concretes [12]. Through scanning electron microscope (SEM) analysis, Pezzi et al. [13] observed that the number of voids increased with larger amount of PET aggregates being used. The results showed large gaps and cracks between cement paste and plastic aggregates, which indicated a weakening in bond.

It was concluded from various reviews that the main reason behind all the changes in the properties of concrete is the weak bonding between plastic aggregates and cement paste. Some research has suggested improving the bonds by performing surface modification using chemical treatments on the plastic aggregates. It is expected that the characteristics of the ITZ may be affected by a chemical reaction between the aggregates and the cement paste [14]. However, only limited studies have been performed on this topic. A successful study performed by Naik et al. [15] demonstrated that treating plastic using an oxidizing agent could strengthen the bond of plastic to cement, thus producing concrete with higher strength. This study investigated plastic treatment using 3 oxidizing agents: water, bleach (hypochlorite), and bleach with sodium hydroxide (alkaline bleach) on concrete properties. As the amount of plastic aggregates in concrete increased, the compressive strength of concrete decreased as predicted, but the compressive strength was greatly improved after the plastics underwent chemical treatment. Naik et al. [15] further theorized that the reaction between the plastic and oxidizing agent created reactive chemical species on the plastic surface that could take part in cementitious reaction. Treatment with hypochlorite introduces the $\mathrm{R}-\mathrm{OH}$ (alcohol) and $\mathrm{R}-\mathrm{COOH}$ (carboxylic acid) species to the polymeric chain of plastic. These species are polar and hydrophilic, which allows stronger hydrogen bonds to be formed. The polarity also increased the reactivity between the plastic aggregates with the cement paste.

Very limited studies have been conducted for chemically treated plastic aggregates used in concrete. Therefore, this study was performed to add more insights of chemically treated plastic aggregates for concrete application. The chemical treatment was performed using hydrogen peroxide solution $\left(\mathrm{H}_{2} \mathrm{O}_{2}\right)$ and calcium hypochlorite solution $\left(\mathrm{Ca}(\mathrm{ClO})_{2}\right)$. The effects of chemical treatment on workability, density, compressive strength, and permeability were investigated. Finally, analysis of variance (ANOVA) is performed at $5 \%$ significance level to check any significant difference between the means of the groups statistically.

\section{Methodology}

2.1. Materials. Materials used in this study include water, ordinary Portland cement (OPC), sand as fine aggregates, crushed rocks, and PET plastic aggregates as coarse aggregates. Crushed PET wastes were used to replace coarse aggregates with different percentages. The plastic aggregates were produced by crushing recycled plastic bottles and food containers using a machine into sizes ranging from 10 to $20 \mathrm{~mm}$. Before mixing with concrete, the plastic aggregates were treated separately by soaking in different oxidizing agents for 24 hours. Then, the treated plastic aggregates were air-dried to ensure there was no additional water or chemicals on the surface. The oxidizing agents used were $2.5 \%$ wt. hydrogen peroxide solution $\left(\mathrm{H}_{2} \mathrm{O}_{2}\right)$ and 5\%wt. calcium hypochlorite solution $\left(\mathrm{Ca}(\mathrm{ClO})_{2}\right)$, which is used in bleaching powder as well. The plastic aggregates treated using water $\left(\mathrm{H}_{2} \mathrm{O}\right)$ was used as control. Figure 1 shows PET plastic aggregates before and during the treatment process.

2.2. Concrete Mix Design. The concrete mix design was calculated based on British Standard (BS) of mix proportioning. In this study, coarse aggregates (natural crushed rocks) were replaced with $0 \%, 10 \%, 20 \%$, and $30 \%$ of plastic aggregates by volume. To determine the mix proportions, 


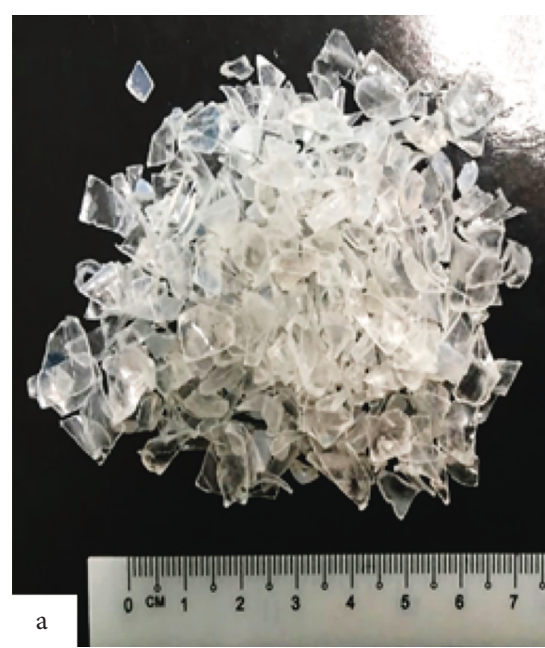

(a)

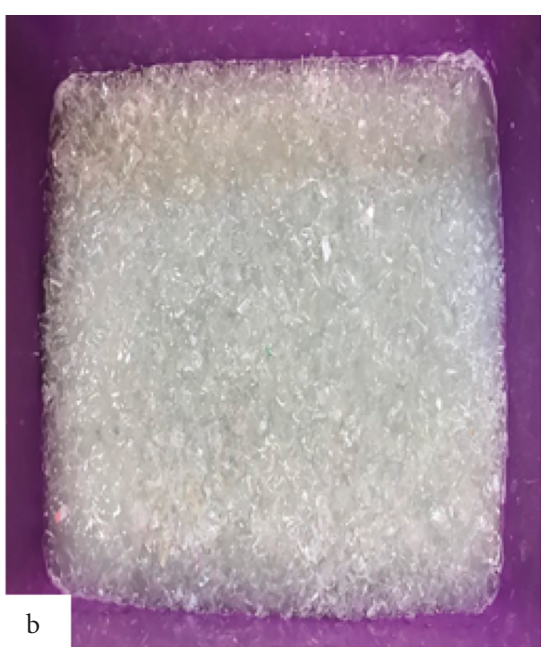

(b)

FIgURE 1: Sample of PET plastic aggregates (a) before treatment and (b) during the chemical treatment process.

the combined specific gravity of the aggregates was calculated. Sieve test and Pycnometer test were conducted to determine the fineness modulus and specific gravity of the aggregates. Figure 2 shows the results of the sieve analysis. The specific gravity of the fine, coarse, and plastic aggregates was $2.79,2.85$, and 1.3 , respectively. The mix designs for the plastic aggregate concretes (PAC) are shown in Table 1.

2.3. Preparation of Specimens. Casting and compaction were done according to BS1881-108:1983. Concrete cubes were casted using $100 \times 100 \times 100 \mathrm{~mm}$ moulds for compressive strength tests. For permeability testing, $150 \times 150 \times 150 \mathrm{~mm}$ cube samples were casted in accordance with BS EN12390-8: 2000. Compaction was done using a vibrating table. Vibration was stopped once no air bubbles could be seen at the surface and a smooth surface was obtained. The casted specimens were covered to prevent moisture loss during hardening of concrete. After 24 hours, the specimens were taken out from the moulds and cured in water for 7 days and 28 days. Curing was done in accordance with BS 1881-111: 1983.

2.4. Testing Methods. To evaluate the fresh concrete properties, slump and density were measured in accordance with BS 1881-102:1983 and BS EN12350-6:2009, respectively. The slump test was performed using a cone mould and a tamping rod. The density test was performed by filling a container with concrete mix and then compacting and weighing the container. Hardened concrete cubes were tested for compressive strength at ages of 7 and 28 days, in accordance with BS 1881-116:1983. The concrete cubes were tested using a compression machine with a loading rate of $2500 \mathrm{~N} / \mathrm{s}$. Permeability of hardened concrete was obtained by measuring the depth of water penetration after samples were subjected to pressure for 72 hours, as stated in BS EN12390$8: 2000$. For the purpose of the test, a digimatic concrete impermeability apparatus was used.

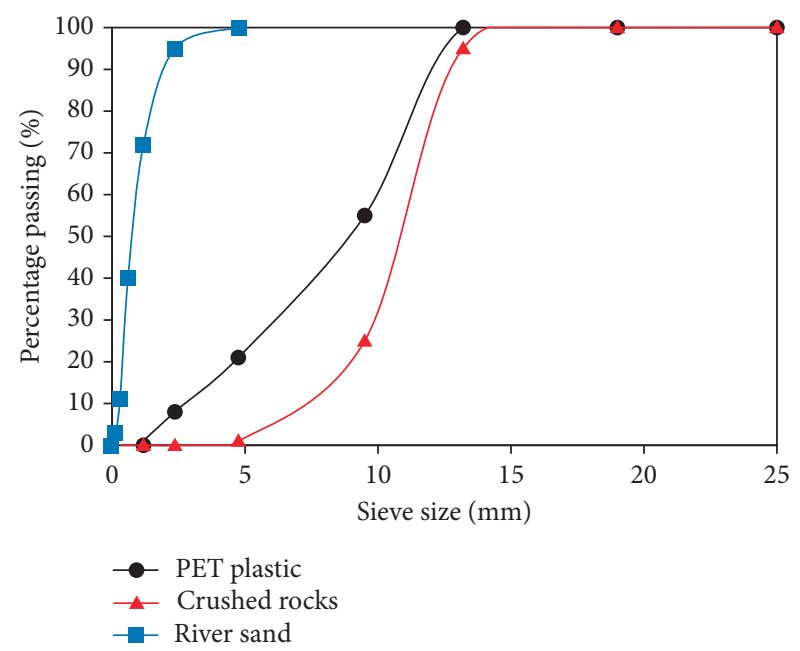

Figure 2: Sieve analysis of plastic, fine, and coarse aggregates used in this study.

TABLE 1: Concrete mix design used in this study.

\begin{tabular}{lccccccc}
\hline Mixture & $\begin{array}{c}\% \\
\text { plastic }\end{array}$ & $\begin{array}{c}\mathrm{w} / \mathrm{c} \\
\text { ratio }\end{array}$ & $\begin{array}{c}\text { Water } \\
\left(\mathrm{kg} / \mathrm{m}^{3}\right)\end{array}$ & $\begin{array}{c}\text { Cement } \\
\left(\mathrm{kg} / \mathrm{m}^{3}\right)\end{array}$ & $\begin{array}{c}\text { F.A } \\
\left(\mathrm{kg} / \mathrm{m}^{3}\right)\end{array}$ & $\begin{array}{c}\text { C.A } \\
\left(\mathrm{kg} / \mathrm{m}^{3}\right)\end{array}$ & $\begin{array}{c}\text { P.A } \\
\left(\mathrm{kg} / \mathrm{m}^{3}\right)\end{array}$ \\
\hline M0 & 0 & 0.6 & 230 & 383 & 971 & 896 & 0 \\
M10 & 10 & 0.6 & 230 & 383 & 929 & 679 & 179 \\
M20 & 20 & 0.6 & 230 & 383 & 903 & 486 & 347 \\
M30 & 30 & 0.6 & 230 & 383 & 882 & 305 & 509 \\
\hline
\end{tabular}

Note: w/c ratio: water-cement ratio; F.A: fine aggregates; C.A: coarse aggregates; P.A: plastic aggregates.

To evaluate the microstructure of the concrete specimens, a SEM was used to obtain images under high magnification. Elemental identification was also performed using energy-dispersive X-ray spectroscopy (EDX) analysis. The test was done on 3 samples to compare the gap between treated plastic aggregates (using $\mathrm{H}_{2} \mathrm{O}, \mathrm{H}_{2} \mathrm{O}_{2}$, and $\mathrm{Ca}(\mathrm{ClO})_{2}$ ) and the cementitious matrix. The concrete samples were cured for 28 days and coated with platinum (Pt) to obtain a 
clearer image under the microscope. Using backscattered electron mode, an accelerating voltage of $15 \mathrm{kV}$ with magnification of 20,000 was set for all three samples.

\section{Results and Discussion}

3.1. Fresh Concrete Properties. Fresh concrete properties of slump and density were measured for concrete with different proportion of treated plastic aggregates using either $\mathrm{H}_{2} \mathrm{O}$, $\mathrm{H}_{2} \mathrm{O}_{2}$, or $\mathrm{Ca}(\mathrm{ClO})_{2}$. Figure 3 shows the fresh density results for concrete with various plastic aggregate amounts. Overall, the fresh densities decreased with increasing the amount of plastic aggregates as expected. Since plastic aggregates have a lower density than natural coarse aggregates, the overall weight of concrete is reduced, thereby producing a lighter concrete.

The typical density of normal weight concrete ranges between 2200 and $2400 \mathrm{~kg} / \mathrm{m}^{3}$, while lightweight concrete density is below $2200 \mathrm{~kg} / \mathrm{m}^{3}$ [9]. From the results shown in Figure 3 , the density of concrete with plastic aggregates was below $2200 \mathrm{~kg} / \mathrm{m}^{3}$, thereby being classified as lightweight concrete. The potential application of plastic aggregates concrete (PAC) may noticeably reduce the dead load of whole structure which is an important design consideration. Comparing the fresh densities of PAC treated with three different types of oxidizing agents, no distinct patterns could be observed from the results. It could be concluded that different chemical treatment used in this study has insignificant impact on the density of the concrete.

Figure 4 presents the slump values of PAC using various amounts of treated plastic aggregates. Overall, the results indicated that slump increased with an increasing percentage of plastic aggregates. The increase could be explained by the smoother surface and texture of plastic aggregates as compared with natural coarse aggregates, even though the PET aggregates surface area-to-volume ratio for plastic aggregates was higher than that of the natural coarse aggregates. Furthermore, smooth surfaces have weaker binding force to cement paste as the area of contact is lesser.

In addition, it was found that the slump values varied slightly between the control and other two chemicals used in PAC. Amongst the three oxidizing agents, the slump value for $\mathrm{Ca}(\mathrm{ClO})_{2}$ was the lowest, followed by $\mathrm{H}_{2} \mathrm{O}_{2}$ and $\mathrm{H}_{2} \mathrm{O}$. The plastic aggregates undergo surface modification due to oxidation reaction with oxidizing agents, and $\mathrm{Ca}(\mathrm{ClO})_{2}$ is the strongest oxidizing agent, followed by $\mathrm{H}_{2} \mathrm{O}_{2}$ and $\mathrm{H}_{2} \mathrm{O}$ [16]. Treating the plastic with $\mathrm{Ca}(\mathrm{ClO})_{2}$ may modify the initially smooth surface to be more angular and rougher, resulting in more contact and higher friction between the particles, therefore causing a lower slump and workability.

3.2. Compressive Strength. The 7-day and 28-day compressive strengths for all mixtures are presented in Figure 5. Overall, the results showed a decrease in compressive strength as the percentage replacement increased for all PAC types. Compressive strengths for $10 \%$ and $20 \%$ replacements were higher than the minimum compressive strength required for structural concrete, which is approximately

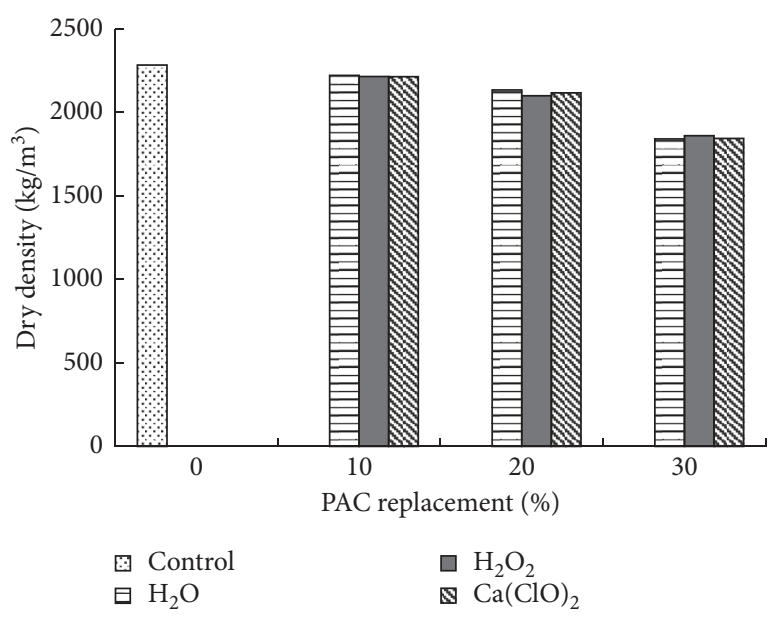

FIGURE 3: Fresh density of concrete with various percentage replacements of plastic aggregates with different chemical treatments.

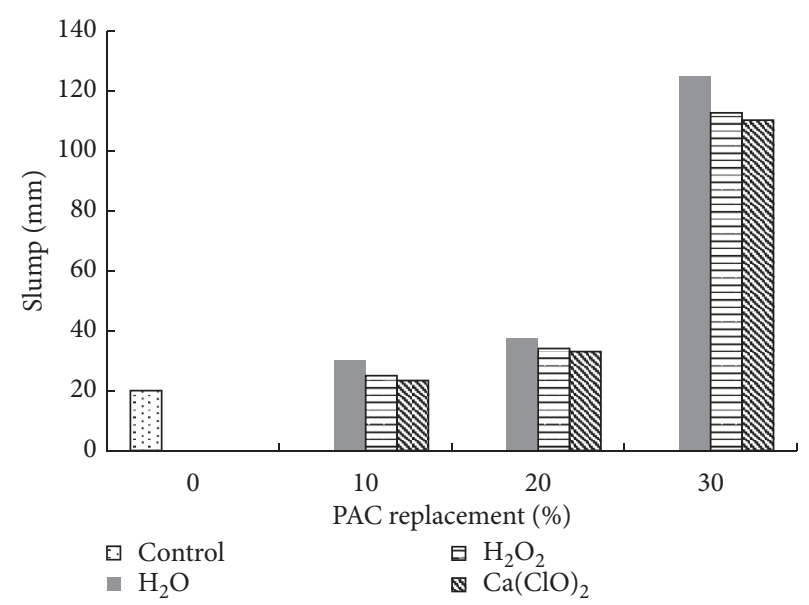

FIGURE 4: Slump of concrete with various percentage replacements of plastic aggregates with different chemical treatments.

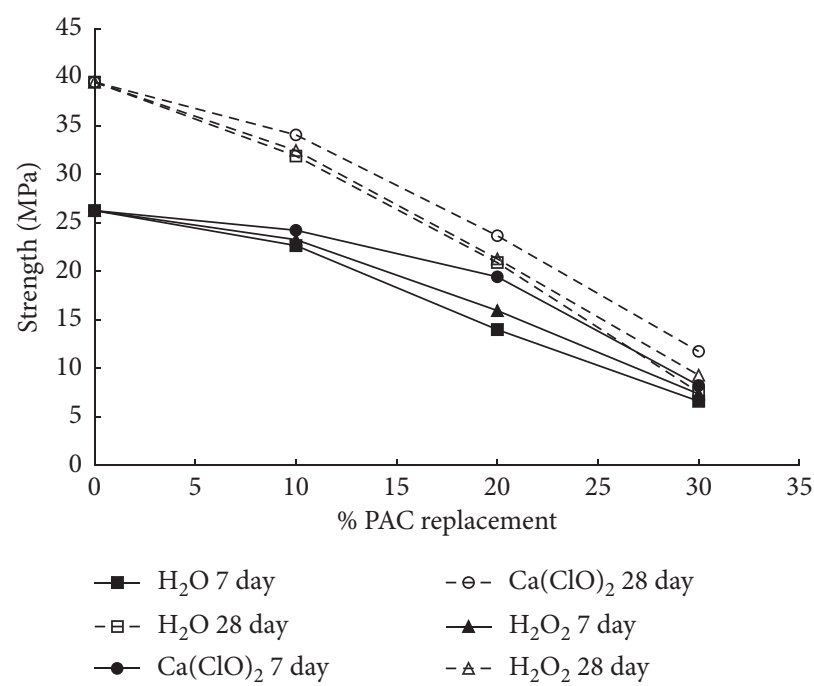

Figure 5: Compressive strength of concrete at 7 and 28 days. 
$17 \mathrm{MPa}$ [9]. This further proved that concrete with plastic aggregates can be used in structural applications, provided that the percentage replacement is lower than $30 \%$.

Overall, the compressive strength for concrete with chemically treated plastic aggregates was higher than that of the control PAC. This could be attributed to the different bond strength between the cement paste and plastic aggregates. After being treated with chemicals, oxidation of plastic surface allows a stronger bond to be formed between plastic and cement paste, due to the reduced hydrophobicity after surface modification. It could be seen from Figure 5 that the highest compressive strength was obtained by using plastic aggregates treated with $\mathrm{Ca}(\mathrm{ClO})_{2}$ for all percentage replacement for both 7-day and 28-day strengths. $\mathrm{Ca}(\mathrm{ClO})_{2}$ is a stronger chemical as compared with $\mathrm{H}_{2} \mathrm{O}_{2}$, resulting in a higher polarity of the plastic surface after treatment, thus allowing stronger hydrogen bonds to be formed, compared with weaker bonds such as hydrophobic interactions and van der Waals force, i.e., intermolecular forces between the molecules are formed on the surface of untreated plastics.

The percentage of improvement in compressive strength due to chemical treatment was not consistent for different percentage replacements of coarse aggregates by plastic aggregates. As shown in Table 2, the percentage increment of compressive strength compared to the control samples fluctuated for different percentage replacements, where the lowest magnitude of increase was observed for $10 \%$ replacement. This might be due to the difference in proportion of plastic and natural coarse aggregates in the mixtures. Replacing $10 \%$ of plastic aggregates does not significantly affect the homogeneity of the concrete mixtures as much as higher percentages of replacements. The percentage of natural coarse aggregates is still considerably higher than the plastic aggregates replacement. Thus, it can be said that as the percentage replacement increases, the effect of chemically treating the plastic aggregates on concrete strength will be more prominent.

Univariate statistical analyses like ANOVA was done on the 7-day and 28-day compressive strength results for three treatment groups, $\mathrm{H}_{2} \mathrm{O}, \mathrm{H}_{2} \mathrm{O}_{2}$, and $\mathrm{Ca}(\mathrm{ClO})_{2}$, for all percentage replacements. The statistical analysis was performed to determine the effectiveness of chemicals treatment for plastic aggregates to improve concrete compressive strength. An ANOVA test could indicate if there are significant differences between the means of the groups statistically but does not tell where the differences lies, if there are any. The Post hoc Tukey Honest Significant Difference (HSD) test was performed to determine which of the specific groups' mean was different. These analyses were carried out with 5\% significance level.

In ANOVA, the null hypothesis states that there is no significant difference between the means of groups. ANOVA is based on the assumption that the samples have the same variances. Homogeneity of variance is first checked using Levene's test. It is conducted to determine if the ANOVA test can be further performed, as a violation of the test shows that there is a probability of falsely rejecting the null hypothesis. In Levene's test, if the $p$ value is more than 0.05 , then the variances are statistically same. As shown in Table 3, all the $p$ values are more than 0.05 , which means that there is no violation on the assumption of homogeneity of variance.
TABLE 2: Percentage increase in compressive strength as compared to the control PAC $\left(\mathrm{H}_{2} \mathrm{O}\right)$.

\begin{tabular}{lcccccc}
\hline $\begin{array}{l}\text { Type of } \\
\text { chemical } \\
\text { treatment }\end{array}$ & $\begin{array}{c}\text { M10 } \\
\text { 7-day }\end{array}$ & $\begin{array}{c}\text { 28-day } \\
(\%)\end{array}$ & $\begin{array}{c}\text { 7-day } \\
(\%)\end{array}$ & $\begin{array}{c}\text { 28-day } \\
(\%)\end{array}$ & $\begin{array}{c}\text { 7-day } \\
(\%)\end{array}$ & $\begin{array}{c}\text { 28-day } \\
(\%)\end{array}$ \\
\hline $\mathrm{H}_{2} \mathrm{O}_{2}$ & 2.7 & 1.8 & 14.0 & 1.8 & 11.3 & 25.2 \\
$\mathrm{Ca}(\mathrm{ClO})_{2}$ & 6.94 & 6.9 & 38.8 & 13.2 & 24.4 & 55.9 \\
\hline
\end{tabular}

TABLE 3: Statistical analysis results for compressive strength.

\begin{tabular}{lcccccc}
\hline \multirow{2}{*}{ Type } & \multicolumn{2}{c}{ M10 } & \multicolumn{2}{c}{ M20 } & \multicolumn{2}{c}{ M30 } \\
& 7-day & 28-day & 7-day & 28-day & 7-day & 28-day \\
\hline $\begin{array}{l}\text { Levene statistic, } \\
p \text { value }\end{array}$ & 0.248 & 0.135 & 0.313 & 0.077 & 0.130 & 0.383 \\
$\begin{array}{l}\text { ANOVA } \\
p \text { value }\end{array}$ & 0.010 & 0.002 & 0.000 & 0.000 & 0.001 & 0.000 \\
$\eta_{p}^{2}$ & 0.402 & 0.498 & 0.901 & 0.905 & 0.913 & 0.934 \\
\hline
\end{tabular}

The output of one-way ANOVA $F$ test is a $p$ value that states there is a significant statistical difference between means of group when the $p$ value is less or equal to 0.05 . The results for $p$ values in Table 3 for all PAC groups have values less than 0.05 , indicating the null hypothesis can be rejected. The $p$ values are very low and close to zero, which shows compelling evidence against null hypothesis. This means that there is an overall effect of chemically treating the plastic aggregates on strength. As discussed previously, this effect is known to positively increase the 7-day and 28-day compressive strengths.

To quantify effects of chemical treatment, the magnitude of mean differences between groups was calculated using partialeta square $\left(\eta_{p}^{2}\right)$. A higher value of $\eta_{p}^{2}$ indicates higher magnitude of differences. Most of the results in Table 3 show that the differences are large, indicating strong effect of chemical treatment on the concrete compressive strength. Table 4 presents the results of the Tukey HSD test. The mean differences between each pair of means in categories 1 and 2 were compared to obtain the statistical significance, $p$ (sig). This identifies specifically which groups or chemical can increase the compressive strength when $p$ (sig) is less than 0.05 .

The results validated the previous findings that as the percentage of plastic replacement increases, the effect of chemical treatment on the 7-day and 28-day strength becomes more substantial. Also, the values corroborates that $\mathrm{Ca}(\mathrm{ClO})_{2}$ treatment is the most effective in increasing the strength of concrete as compared to the control PAC strength. For $10 \%$ replacement, the usage of $\mathrm{H}_{2} \mathrm{O}_{2}$ on plastic aggregates does not have any significant impact on the strength as compared to the control, but using $\mathrm{Ca}(\mathrm{ClO})_{2}$ shows a change. For $20 \%$ replacement, the usage of $\mathrm{H}_{2} \mathrm{O}_{2}$ on plastic aggregates has an impact on the 7-day strength but not the 28-day strength. For 30\% replacement, treating plastic aggregates with $\mathrm{H}_{2} \mathrm{O}_{2}$ indicates an improvement for both 7- and 28-day strengths, but the usage of $\mathrm{Ca}(\mathrm{ClO})_{2}$ is effective in increasing all strengths for $20 \%$ and 30\% replacements. Thus, using the chemicals, $\mathrm{Ca}(\mathrm{ClO})_{2}$ and $\mathrm{H}_{2} \mathrm{O}_{2}$, to treat the plastic has significant differences than using 
Table 4: Post Hoc Tukey HSD test showing the statistical significance $(p(\operatorname{sig}))$ between the three groups.

\begin{tabular}{lccccccc}
\hline \multirow{2}{*}{ Category 1 } & Category 2 & 7-day & M10 & 28-day & 7-day & 28-day & M30 \\
& & 0.402 & 0.537 & $0.001^{*}$ & 0.249 & $0.024^{*}$ & $0.020^{*}$ \\
\multirow{2}{*}{$\mathrm{H}_{2} \mathrm{O}$} & $\mathrm{H}_{2} \mathrm{O}_{2}$ & $0.008^{*}$ & $0.002^{*}$ & $0.000^{*}$ & $0.000^{*}$ & $0.001^{*}$ & $0.000^{*}$ \\
\hline \multirow{2}{*}{$\mathrm{H}_{2} \mathrm{O}_{2}$} & $\mathrm{Ca}(\mathrm{ClO})_{2}$ & 0.402 & 0.537 & $0.001^{*}$ & 0.249 & $0.024^{*}$ & $0.020^{*}$ \\
& $\mathrm{H}_{2} \mathrm{O}$ & 0.113 & $0.020^{*}$ & $0.000^{*}$ & $0.000^{*}$ & $0.012^{*}$ & $0.004^{*}$ \\
\multirow{2}{*}{$\mathrm{Ca}(\mathrm{ClO})_{2}$} & $\mathrm{Ca}(\mathrm{ClO})_{2}$ & $0.008^{*}$ & $0.002^{*}$ & $0.000^{*}$ & $0.000^{*}$ & $0.001^{*}$ & $0.000^{*}$ \\
& $\mathrm{H}_{2} \mathrm{O}$ & 0.113 & $0.020^{*}$ & $0.000^{*}$ & $0.000^{*}$ & $0.012^{*}$ & $0.004^{*}$ \\
\hline
\end{tabular}

${ }^{*}$ The mean difference is significant at the 0.05 level.

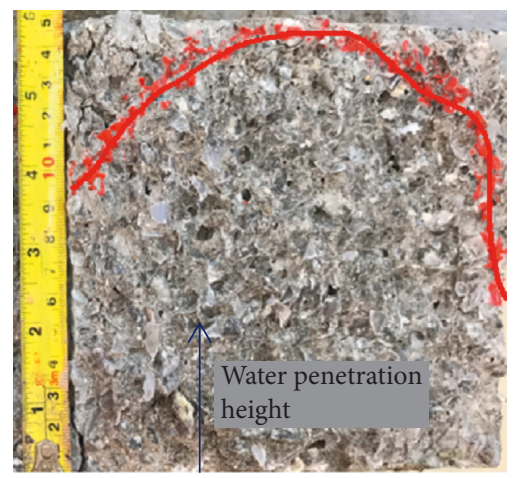

(a)

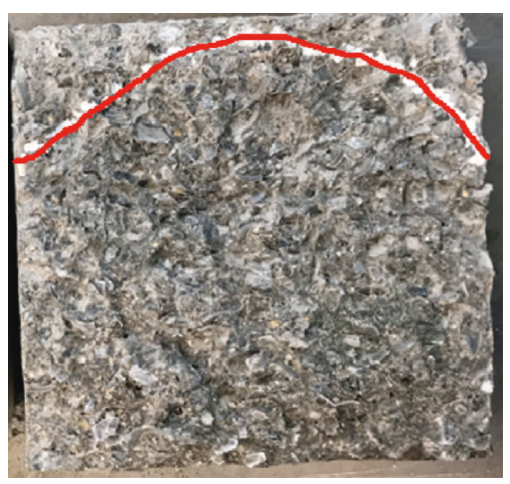

(b)

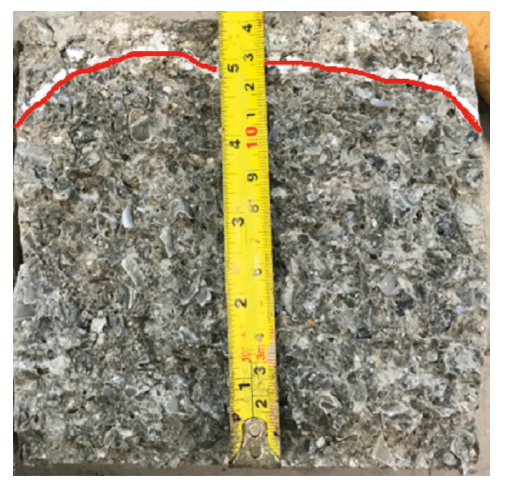

(c)

FIgure 6: Water penetration depth for PAC with PET aggregates treated with (a) $\mathrm{H}_{2} \mathrm{O},(\mathrm{b}) \mathrm{H}_{2} \mathrm{O}_{2}$, and $(\mathrm{c}) \mathrm{Ca}(\mathrm{ClO})_{2}$.

$\mathrm{H}_{2} \mathrm{O}$, but predominantly, $\mathrm{Ca}(\mathrm{ClO})_{2}$ produces better strength results.

3.3. Water Permeability and Porosity. The water penetration rate was tested for three concrete samples incorporated with different types of treated PET aggregates. This was only done for $20 \%$ replacement, as the main purpose was to compare the effect of different chemical treatments on the water permeability. It was previously determined that $10 \%$ plastic replacements do not show significant effect on the concrete while $30 \%$ is not suitable for structural application purposes. Therefore, $20 \%$ replacement was considered to be the most optimum percentage of replacement.

From Figure 6, it could be seen that the height of water penetrated into the concrete under pressure was the highest for the control PAC, followed by the PAC with $\mathrm{H}_{2} \mathrm{O}_{2}$ - and $\mathrm{Ca}(\mathrm{ClO})_{2}$-treated PET aggregates. Table 5 shows the water penetration rate for each of the PAC type. Compared with the control, the reduction in the rate was $1.5 \%$ and $6.6 \%$ for PAC with $\mathrm{H}_{2} \mathrm{O}_{2}$ and $\mathrm{Ca}(\mathrm{ClO})_{2}$, respectively. These results corroborate with the inverse relationship between permeability and compressive strength, as the control PAC produces the lowest strength and $\mathrm{PAC}$ with $\mathrm{Ca}(\mathrm{ClO})_{2}$-treated PET aggregates has the highest strength for any percentage of PET replacements.

Generally, the bonding strength between cement paste and PET aggregates also influences the permeability of concrete. The permeability of the concrete decreased when PET aggregates were treated using chemicals, as the introduction of stronger bonds reduced the gap between the
TABLE 5: Water penetration rates for different chemical treatments used on PET aggregates.

\begin{tabular}{lc}
\hline Type of treatment & Water penetration rate $(\mathrm{mm} / \mathrm{hr})$ \\
\hline $\mathrm{H}_{2} \mathrm{O}$ & 1.96 \\
$\mathrm{H}_{2} \mathrm{O}_{2}$ & 1.93 \\
$\mathrm{Ca}(\mathrm{ClO})_{2}$ & 1.83 \\
\hline
\end{tabular}

cement paste and plastic aggregates. When the gaps between particles reduced, the number of pores decreases and the pore system becomes more discontinuous and ineffective in transportation of fluid, thereby causing permeability to decrease. As discussed previously, it is evident that a stronger oxidizing agent helps forming in a stronger bonding between plastics and cement paste, meaning that the concrete with plastic treated using $\mathrm{Ca}(\mathrm{ClO})_{2}$ is expected to have smaller gaps in between the particles, thus lowering the permeability as compared with $\mathrm{H}_{2} \mathrm{O}_{2}$.

Permeability can also be related to porosity in terms of the amount of water infiltrating the pores of the concrete samples. It can be deduced that for a less permeable concrete, the porosity also decreases as there are less diffusive pathways available for the water to permeate through the pores. Therefore, the PAC with $\mathrm{Ca}(\mathrm{ClO})_{2}$-treated plastic aggregates can have the lowest permeability and porosity.

3.4. Microstructure Analysis. Figure 7 shows images from the SEM, and Figure 8 shows the EDX analysis of elements compositions in the different concrete mixes. C-S-H foil-like 


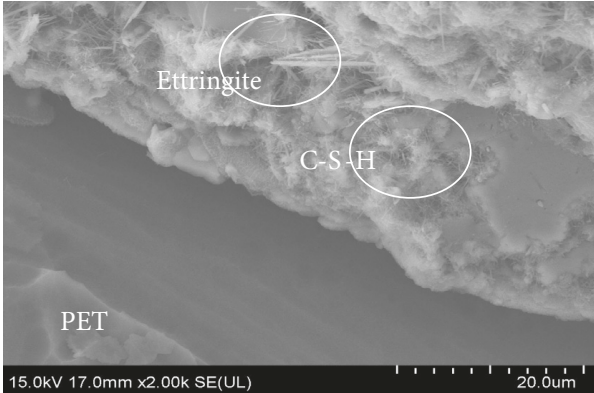

(a)

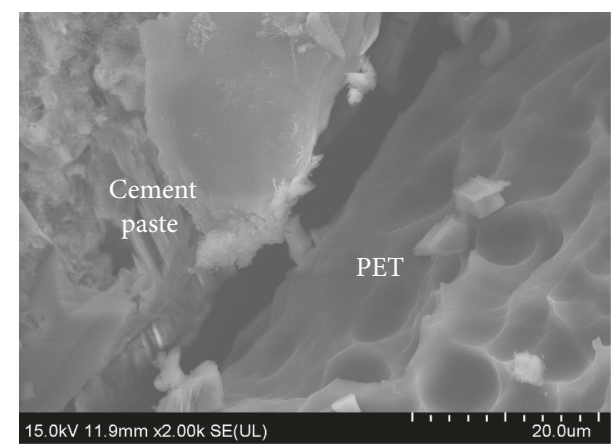

(b)

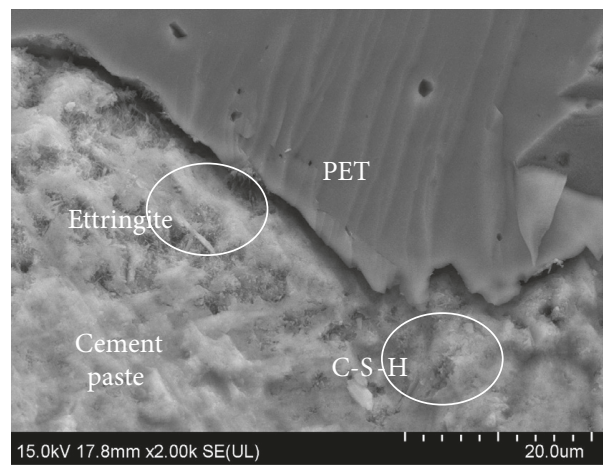

(c)

FIGURE 7: SEM images showing the contact between cementitious matrix and PET plastic aggregate treated with (a) $\mathrm{H}_{2} \mathrm{O}$, (b) $\mathrm{H}_{2} \mathrm{O}_{2}$, and (c) $\mathrm{Ca}(\mathrm{ClO})_{2}$.

fibres and bundles can be seen along with plate-like calciumhydroxide $(\mathrm{C}-\mathrm{H})$ morphology. It can be observed that the PET treated with $\mathrm{H}_{2} \mathrm{O}$ has smooth surfaces, whereas the rough surfaces can be seen in PET treated with $\mathrm{H}_{2} \mathrm{O}_{2}$ and $\mathrm{Ca}(\mathrm{ClO})_{2}$. Figure $7(\mathrm{~b})$ shows that the PET treated by $\mathrm{H}_{2} \mathrm{O}_{2}$ has holes and uneven surfaces. In Figure $7(\mathrm{c})$, the PET treated by $\mathrm{Ca}(\mathrm{ClO})_{2}$ has cracks and more groove lines in addition to some holes. This validates the findings which previously concluded that the concrete with $\mathrm{Ca}(\mathrm{ClO})_{2^{-}}$ treated plastic aggregates has the roughest surface and lowest slump values.

As stated previously, treating the PET aggregates with chemicals causes the surface to roughen due to oxidation. Chemical oxidation modifies the surface of PET aggregates by introducing polar groups so that hydrogen bonds can be formed between the cement paste and PET aggregates to improve adhesive properties. Without chemical treatment, the bonds formed are nonpolar van der Waals force, which is considered to be weaker.

The improvement in bonding was also observed from the SEM images, which showed the quality of interaction between the cement paste and the PET plastic aggregate in the ITZ. By comparing the gap size, the largest gap could be observed in the control PAC while the smallest gap was observed in the PAC with $\mathrm{Ca}(\mathrm{ClO})_{2}$-treated plastic aggregates. The measured gaps between the cement paste and PET aggregate for $\mathrm{H}_{2} \mathrm{O}, \mathrm{H}_{2} \mathrm{O}_{2}$, and $\mathrm{Ca}(\mathrm{ClO})_{2}$ were given as $605 \mathrm{~nm}, 490 \mathrm{~nm}$, and $347 \mathrm{~nm}$, respectively. Therefore, it can be concluded that PET aggregates treated with $\mathrm{Ca}(\mathrm{ClO})_{2}$ shows the highest bonding strength between the cement paste and aggregates, which can be related to a concrete with higher compressive strength, lower permeability, and porosity.

Based on the results from the elemental analysis in EDX in Figure 8, $\mathrm{Ca}, \mathrm{C}, \mathrm{Si}, \mathrm{O}$, and $\mathrm{Al}$ element peaks could be found in all images spectrums selected at the cement matrix. The low Al peak at the cement matrix indicates a low amount of ettringite. Needle-shaped ettringite crystals can be seen dispersed around the cement matrix. Ettringite is not beneficial at the later ages in concrete as it will reduce the durability of concrete and cause cracking. At severe environments, ettringite becomes highly unstable. Minor amounts of secondary ettringite are still acceptable in hardened concretes.

There are relatively high peaks for $\mathrm{Ca}$ in the spectrums at the cement paste. $\mathrm{Ca} / \mathrm{Si}$ ratio is an important factor for the hydration of cement, which affects the strength of concrete. The ratio of $\mathrm{Ca} / \mathrm{Si}$ was also determined from the spectrums for cement paste in all EDX images in Figure 8. The $\mathrm{Ca} / \mathrm{Si}$ ratio for the concrete with different plastic aggregates treated using $\mathrm{H}_{2} \mathrm{O}, \mathrm{H}_{2} \mathrm{O}_{2}$, and $\mathrm{Ca}(\mathrm{ClO})_{2}$ was 5.5 , 4.9, and 3.3, respectively. A lower $\mathrm{Ca} / \mathrm{Si}$ ratio typically gives higher strength for any hydration times. For a decreasing $\mathrm{Ca} / \mathrm{Si}$ ratio, the molar volume C-S-H phases decreases, resulting in a larger contact area between cement matrix and aggregates, stronger bonding, and compressive strength. [17].

In summary, PET waste obtained from the bottles and food containers can be reused as plastic aggregates for 


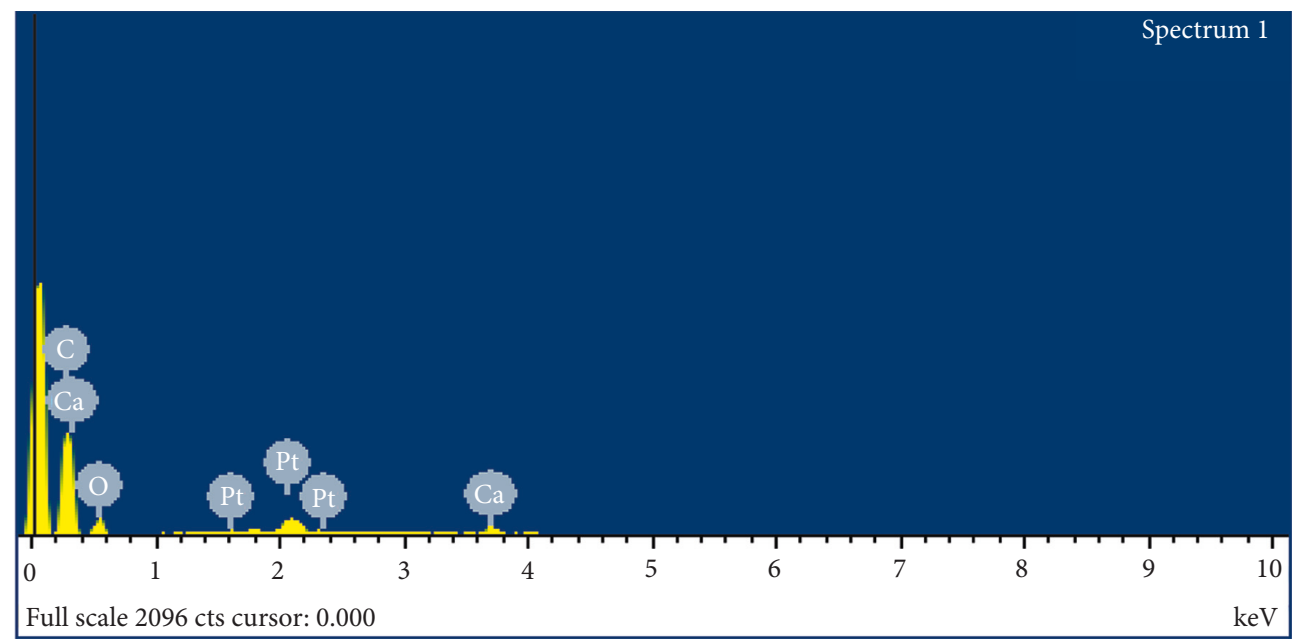

(a)

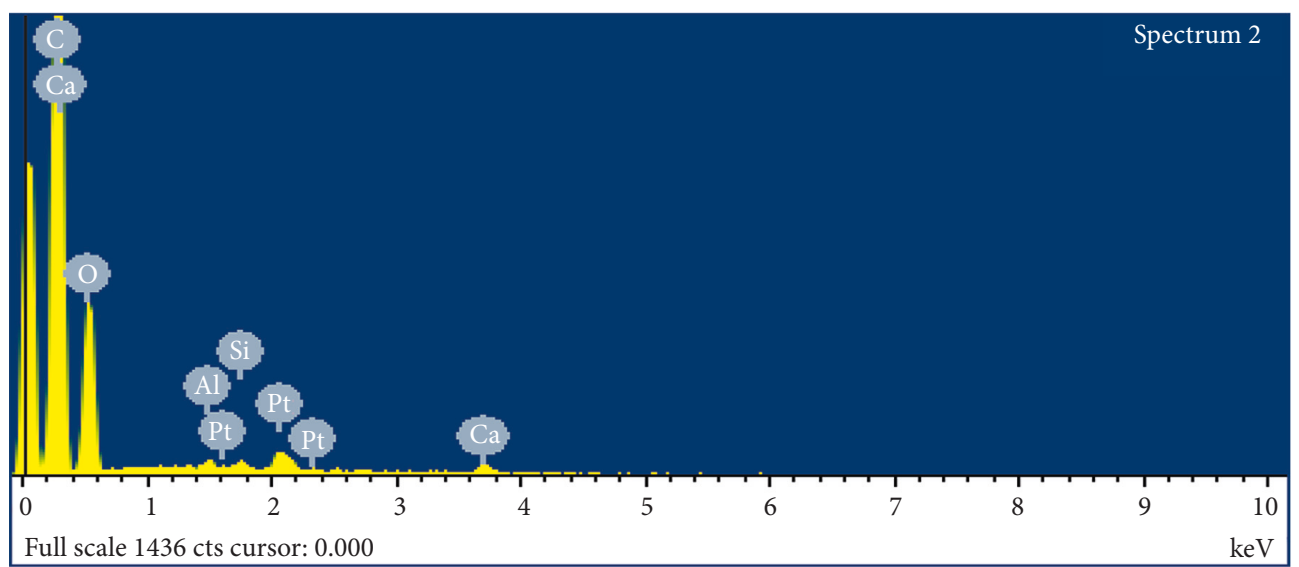

(b)

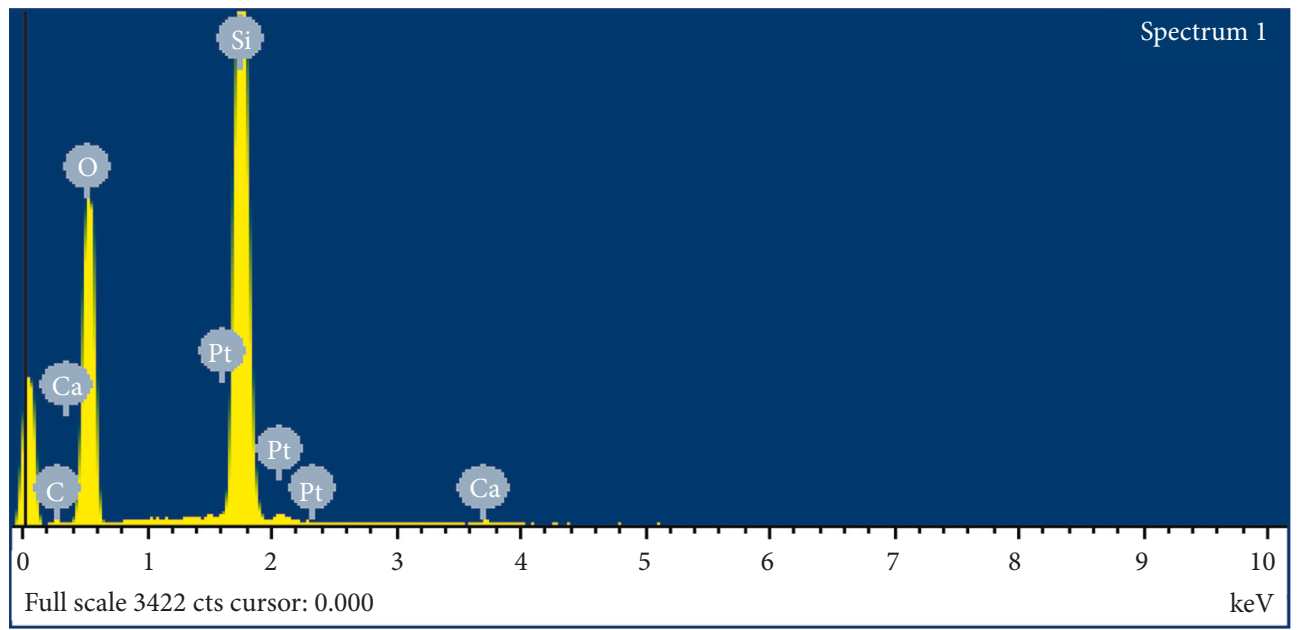

(c)

FIgURE 8: EDX analysis showing the elemental compositions of concrete in PET plastic aggregate treated with (a) $\mathrm{H}_{2} \mathrm{O}$, (b) $\mathrm{H}_{2} \mathrm{O}_{2}$, and (c) $\mathrm{Ca}(\mathrm{ClO})_{2}$.

concrete. When the PET aggregates are chemically treated before being incorporated in concrete, an improvement in the physical and mechanical properties can be achieved. For application of the study, PAC can be used in structural and nonstructural applications as the minimum compressive strength is achieved, provided that the percentage replacement is not above $30 \%$. Some of the applications include road, highways, pavements, and medians. Therefore, there is a potential for this method to be advanced in the construction industry. 


\section{Conclusion}

This research work contributed to the development of chemically treated waste polyethylene terephthalate (PET) aggregates in concrete. In this study, PET aggregates were treated using three different types of oxidizing agents such as $\mathrm{H}_{2} \mathrm{O}, \mathrm{H}_{2} \mathrm{O}_{2}$, and $\mathrm{Ca}(\mathrm{ClO})_{2}$. From the outcome of this study, the following conclusions can be drawn:

(i) The workability of concrete decreases when the plastic aggregates were treated using a stronger oxidizing agent of $\mathrm{Ca}(\mathrm{ClO})_{2}$. The slump value of plastic aggregate concrete (PAC) was found to be lower in the $\mathrm{Ca}(\mathrm{ClO})_{2}$-treated waste $\mathrm{PET}$ aggregates than the PET treated with $\mathrm{H}_{2} \mathrm{O}$ and $\mathrm{H}_{2} \mathrm{O}_{2}$.

(ii) Concrete with PET satisfies the lightweight concrete density specification. The density of PAC reduced as the percentage of PET replacement increased. Chemical treatment has no effects on the density of concrete.

(iii) The compressive strength of PAC also reduced as the percentage of PET replacement increased. Chemical treatment on plastic aggregates was effective in improving compressive strength of concrete. Amongst the treatments used, $\mathrm{Ca}(\mathrm{ClO})_{2}$ showed the highest improvement of concrete compressive strength.

(iv) From univariate statistical analysis of ANOVA and Post Hoc Tukey test, it was further established that PET aggregates treated using $\mathrm{Ca}(\mathrm{ClO})_{2}$ had more statistical significant effects on the compressive strength than $\mathrm{H}_{2} \mathrm{O}$ and $\mathrm{H}_{2} \mathrm{O}_{2}$.

(v) Chemical treatment on plastic aggregates reduces the porosity and permeability of concrete. PAC mixed with $\mathrm{PET}$ aggregates treated with $\mathrm{Ca}(\mathrm{ClO})_{2}$ showed a lower permeability than the PET treated with $\mathrm{H}_{2} \mathrm{O}$ and $\mathrm{H}_{2} \mathrm{O}_{2}$.

(vi) In the control mix, weak bonding due to relatively large gaps between the cementitious matrix and PET aggregates was proved by the SEM image analysis. However, the bonding was improved by reducing the gaps between the matrix and aggregates for concrete with $\mathrm{Ca}(\mathrm{ClO})_{2}$-treated $\mathrm{PET}$ aggregates, followed by concrete with $\mathrm{H}_{2} \mathrm{O}_{2}$-treated PET aggregates.

(vii) The elemental analysis results revealed that the concrete with $\mathrm{Ca}(\mathrm{ClO})_{2}$-treated $\mathrm{PET}$ aggregates demonstrated the lowest $\mathrm{Ca} / \mathrm{Si}$ ratio which validates the improvement in the compressive strength of PAC.

In the end, limited research has been done to analyze the effects of chemically pretreating the waste PET aggregates on concrete properties. Further studies on the flexural and tensile strengths of PAC with chemically treated PET as both coarse and fine aggregates can be conducted to widen the application of PAC. Also, further works can be performed to investigate the effects of other types of chemicals which might have stronger oxidizing power to promote better binding of PET aggregates to the cementitious matrix and thus producing concrete with higher strength. Finally, longterm durability of PAC can be analyzed such as thermal properties and corrosion attack to investigate the resistance of PAC towards environmental and surrounding changes.

\section{Data Availability}

All the data used in this study can be made available from the corresponding author upon request.

\section{Conflicts of Interest}

The authors declare that they have no conflicts of interest.

\section{References}

[1] M. H. Kamarudin, M. Y. Yaakob, M. S. Salit, H. H. Pieter, N. A. Badarulzaman, and R. M. Sohaimi, "A review on different forms and types of waste plastic used in concrete structure for improvement of mechanical properties," Journal of Advanced Research in Applied Mechanics, vol. 28, no. 1, pp. 9-30, 2016.

[2] F. K. Alqahtani, G. Ghataora, K. M. Iqbal, S. Dirar, A. Kioul, and M. Al-Otaibi, "Lightweight concrete containing recycled plastic aggregates," in Proceedings of the International Conference on Electromechanical Control Technology and Transportation (ICECTT 2015), pp. 527-533, Zhuhai City, China, October 2015.

[3] M. A. B. Abdullah, S. Tamizi, A. Tamizi, and Y. Zarina, "Investigation of HDPE plastic waste aggregate on the properties of concrete," Journal of Asian Scientific Research, vol. 1, no. 7, pp. 340-345, 2011.

[4] T. Subramani and V. Pugal, "Experimental study on plastic waste as A coarse aggregate for structural concrete," International Journal of Application or Innovation in Engineering \& Management (IJAIEM), vol. 4, no. 5, pp. 144-152, 2015.

[5] N. Saikia and J. de Brito, "Mechanical properties and abrasion behaviour of concrete containing shredded PET bottle waste as a partial substitution of natural aggregate," Construction and Building Materials, vol. 52, pp. 236-244, 2014.

[6] Y. W. Choi, D. J. Moon, Y. J. Kim, and M. Lachemi, "Characteristics of mortar and concrete containing fine aggregate manufactured from recycled waste polyethylene terephthalate bottles," Construction and Building Materials, vol. 23, no. 8, pp. 2829-2835, 2009.

[7] A. Babafemi, B. Savija, S. Paul, and V. Anggraini, "Engineering properties of concrete with waste recycled plastic: a review," Sustainability, vol. 10, no. 11, p. 3875, 2018.

[8] A. M. Neville, Properties of Concrete, Pitman Publishing Ltd., London, UK, 1981.

[9] Z. Z. Ismail and E. A. AL-Hashmi, "Use of waste plastic in concrete mixture as aggregate replacement," Waste Management, vol. 28, no. 11, pp. 2041-2047, 2008.

[10] K. Hannawi, S. Kamali-Bernard, and W. Prince, "Physical and mechanical properties of mortars containing PET and PC waste aggregates," Waste Management, vol. 30, no. 11, pp. 2312-2320, 2010.

[11] M. J. Islam, M. S. Meherier, and A. K. M. R. Islam, "Effects of waste PET as coarse aggregate on the fresh and harden 
properties of concrete," Construction and Building Materials, vol. 125, pp. 946-951, 2016.

[12] G. Bonifazi, G. Capobianco, S. Serranti et al., "The ITZ in concrete with natural and recycled aggregates: study of microstructures based on image and SEM analysis," in Proceedings of the 15th Euroseminar on Microscopy Applied to Building Materials (EMABM 2015), Delft, The Netherlands, June 2015.

[13] L. Pezzi, P. A. De Luca, D. Vuono, F. Chiappetta, and A. Nastro, "Concrete products with waste's plastic material (bottle, glass, plate)," Materials Science Forum, vol. 514-516, pp. 1753-1760, 2006.

[14] J. Ollivier, J. Maso, and B. Bourdette, "Interfacial transition zone in concrete," Advanced Cement Based Materials, vol. 2, no. 1, pp. 30-38, 1995.

[15] T. R. Naik, S. S. Singh, C. O. Huber, and B. S. Brodersen, "Use of post-consumer waste plastics in cement-based composites," Cement and Concrete Research, vol. 26, no. 10, pp. 1489-1492, 1996.

[16] J. Farr, W. Smith, and D. Steichen, "Bleaching agents," in KirkOthmer Encyclopedia of Chemical Technology, vol. 4, pp. 43-81, ACS Publications, Washington, DC, USA, 2013.

[17] W. Kunther, S. Ferreiro, and J. Skibsted, "Influence of the Ca/ Si ratio on the compressive strength of cementitious calciumsilicate-hydrate binders," Journal of Materials Chemistry A, vol. 5, no. 33, pp. 17401-17412, 2017. 


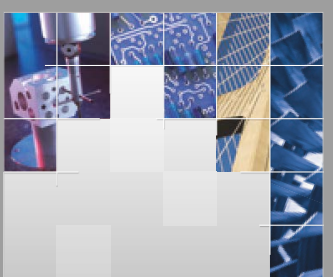

\section{Enfincering}
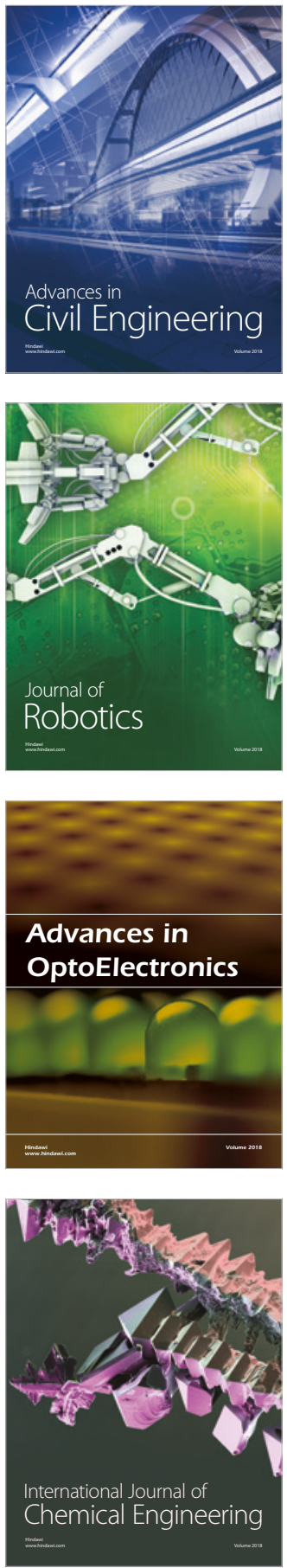

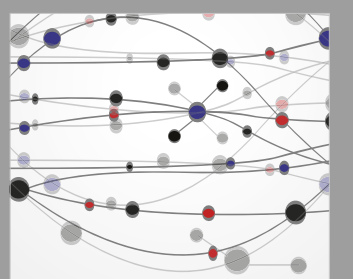

\section{Rotating \\ Machinery}

The Scientific World Journal

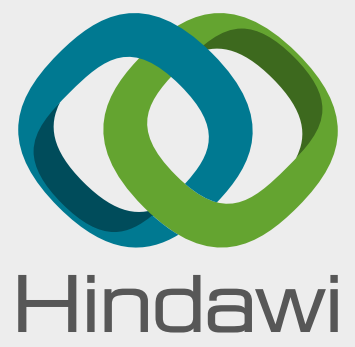

Submit your manuscripts at

www.hindawi.com
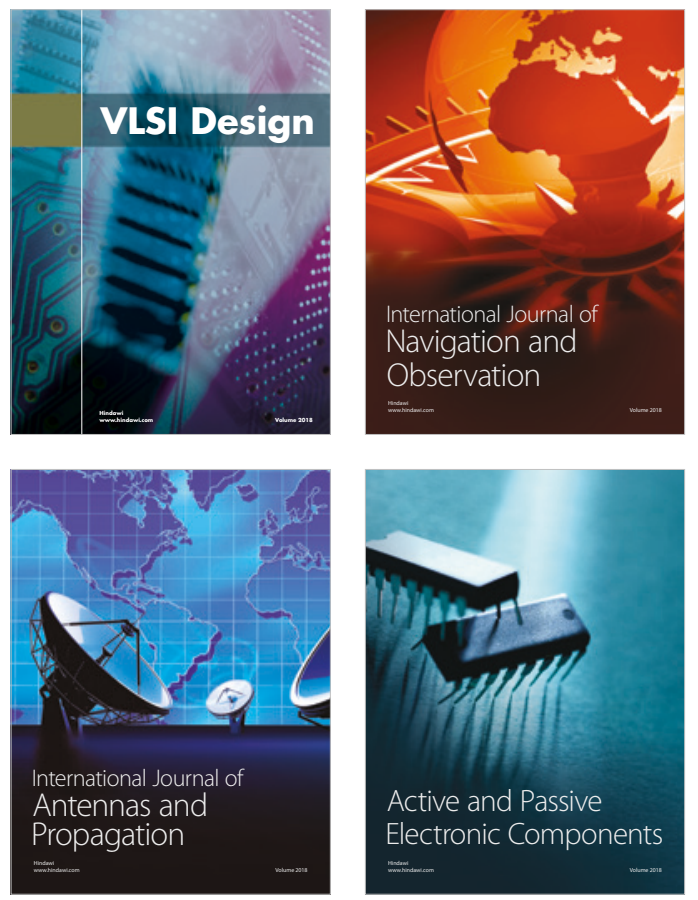
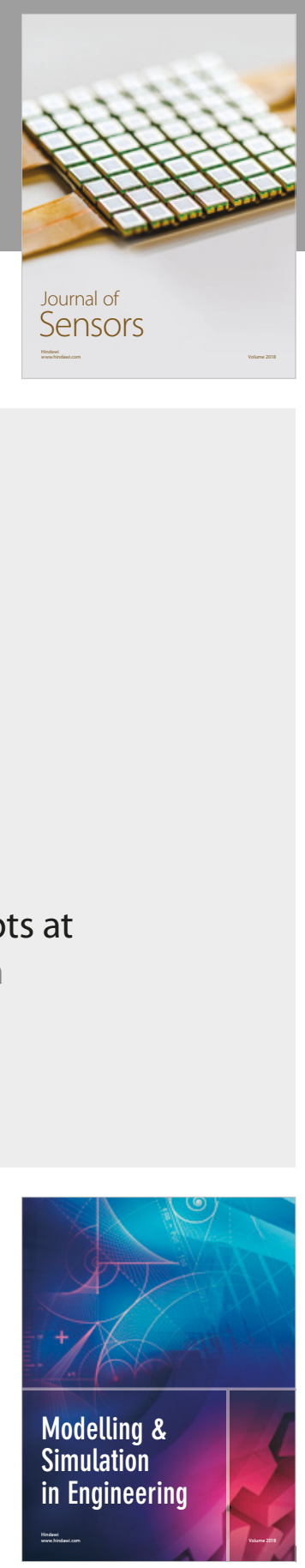

\section{Advances \\ Multimedia}
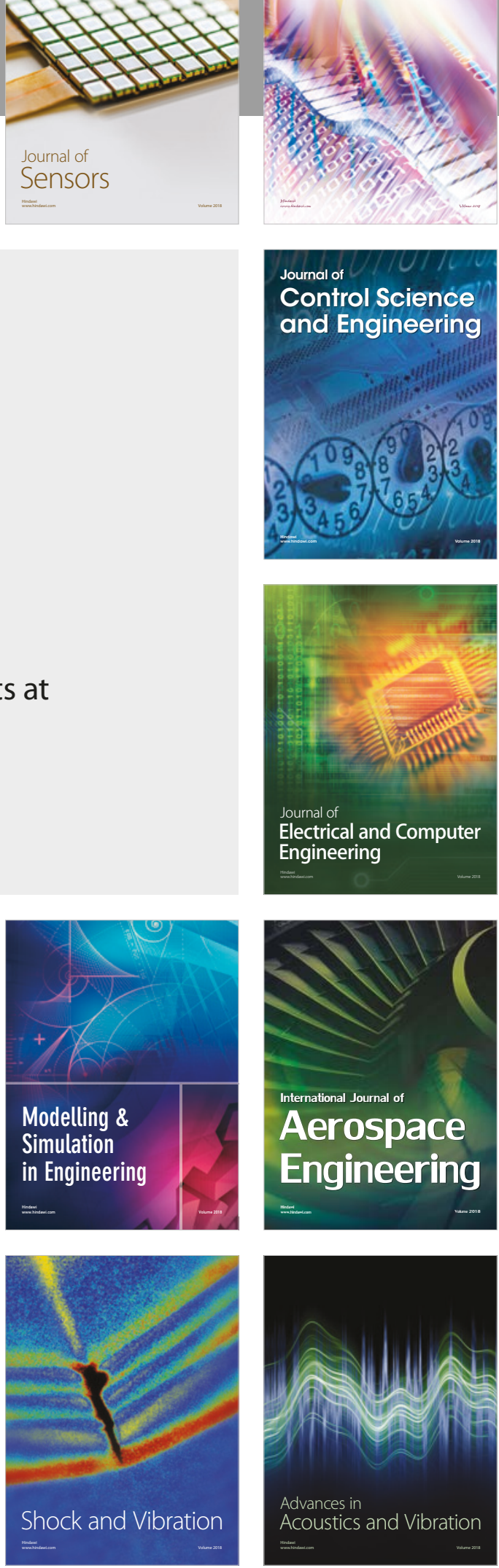